\title{
Variation in Breast Cancer Screening Recommendations by Primary Care Providers Surveyed in Wisconsin
}

\author{
Emily Nachtigal, $M D^{1,2}$ (D), Noelle K. LoConte, $M D^{1,2}$, Sarah Kerch, $M P H^{2}$, \\ Xiao Zhang, $P h D^{2}$, and Amanda Parkes, $\mathrm{MD}^{1,2}$
}

'Department of Internal Medicine, University of Wisconsin School of Medicine and Public HealthMadison, WI, USA; ${ }^{2}$ University of Wisconsin Carbone Cancer CenterMadison, WI, USA.

BACKGROUND: Cancer screening is chiefly performed by primary care providers (PCPs) who rely on organizational screening guidelines. These guidelines provide evidence-based recommendations; however, they are often without unanimity leading to divergent screening recommendations.

OBJECTIVE: Due to the high incidence of breast cancer, the availability of screening methods, and the presence of multiple incongruent guideline recommendations, we sought to understand breast cancer screening practices in Wisconsin to identify patterns that would allow us to improve evidence-based screening adherence.

METHODS: A 46-question survey on breast cancer screening beliefs and practices for average-risk women was sent to healthcare providers in Wisconsin in 2018, who provided cancer screening services to women. Providers included physicians, nurse practitioners (NPs), physician assistants (PAs), and midwives.

RESULTS: A total of 295 people responded to the survey, for a response rate of $28.6 \%$. Most respondents were physicians (64.1\%), followed by NPs (25.7\%), PAs (5.3\%), and midwives (1.5\%). Of physicians, most practiced family medicine (65.3\%), followed by internal medicine (25.3\%) and gynecology (9.4\%). The United States Preventive Services Task Force (USPSTF) was reported as being "very influential" for $60.5 \%$ of providers, followed by the American Cancer Society at $46.8 \%$. For patients $40-49$ years old, $75.6 \%$ of providers performed clinical breast exams and 58.5\% recommended self-breast exams; these numbers increased for women 50+years old to $78.7 \%$ and $61.2 \%$, respectively. Mammography was more likely to be recommended annually for women aged 40-49 rather than biennially by non-physician clinicians compared to physicians $(p<.001)$.

CONCLUSIONS: PCPs in Wisconsin continue to overestimate the efficacy of clinical and self-breast exams as well as overuse these in clinical practice. Providers find multiple screening guidelines influential but favor the USPSTF; however, these guidelines are frequently not being followed. Further research needs to be done to investigate the lack of national guideline adherence by providers to improve compliance with evidence-based screening recommendations.

Prior Presentations University of Wisconsin Carbone Cancer Center Research Retreat, April 4, 2019. Dialogue for Action on Cancer Screening and Prevention, April 24-26, 2019. Wisconsin Public Health Association Annual Public Health Conference Mau 21-23. 2019.

Received October 17, 2019

Accepted May 11, 2020

Published online June 3, 2020
KEY WORDS: breast cancer; cancer screening; primary care providers; Wisconsin

J Gen Intern Med 35(9):2553-9

DOI: $10.1007 / \mathrm{s} 11606-020-05922-y$

(C) Society of General Internal Medicine 2020

\section{INTRODUCTION}

Cancer screening exists to improve the health of a population by detecting cancer at its earliest stage. Screening is often executed using primary care providers (PCPs) who rely on organizational screening guidelines. There are complicated tradeoffs associated with the use of screening tests, which have led to the establishment of conflicting recommendations from multiple organizations. It is not uncommon for various groups to be without unanimity in recommendations, which may lead to confusion and lack of adherence to these guidelines by providers. A prime example of this issue is breast cancer screening, with controversy regarding different modalities, as well timing and frequency of assessment.

Despite this debate, the importance of breast cancer screening is universally accepted. Breast cancer is the most common type of cancer in women and the second leading cause of cancer death among women in the USA, with an estimated 271,270 new breast cancer diagnoses and 42,260 deaths in 2019. ${ }^{1}$ Considering the frequency of diagnosis as well as the existence of available and efficacious screening methods, breast cancer screening is a model example to evaluate preventative screening guideline adherence for average-risk patients. With a 1-in-8 lifetime risk of breast cancer for women in the USA, it is important to understand the preferred screening and early detection methods recommended by primary care providers, as they are the initial providers most average-risk patients see for breast cancer screening and guidance. ${ }^{2}$

Multiple breast cancer screening modalities exist, including clinical breast exam (CBE), self-breast exam (SBE), ultrasound, and MRI. The gold standard of breast cancer screening continues to be mammography, which has been shown to reduce breast cancer mortality in women ages 50-69. ${ }^{3}$ From 1990 to 2015 , breast cancer death rates declined $39 \%$, which is believed to be due to improvements in treatment as well as earlier detection with the use of mammography. ${ }^{2}$ Despite the 
evidence to support mammography, there are variables that augment the magnitude of effectiveness, such as patient age and screening interval. ${ }^{3}$ It has known consequences including possible harm through increased patient discomfort and anxiety, unnecessary biopsies, and detection of indolent breast cancers. ${ }^{4}$ Given the high proportion of overdiagnoses with breast cancer screening, there has been a trend over the last decade to reexamine screening modalities and guidelines. ${ }^{5}$ Furthermore, given the rising financial burden of healthcare, there has been an incentive, such as the Choosing Wisely campaign, to minimize costs whenever possible, which includes decreasing unnecessary screening tests. ${ }^{6}$ The goal is to provide a balance through high-value care that maximizes the benefits of screening, while minimizing potential harms and costs. ${ }^{7}$

While united in their desire to provide concrete breast cancer screening recommendations, screening guidelines often disagree in age, interval screening time, and sometimes, even modality. This not only allows providers some flexibility in their recommendations but also contributes to confusion for providers. For example, the US Preventive Services Task Force (USPSTF) states that the decision to begin mammography in women ages 40-49 years should be an individual one and that women 50-74 years of age should receive biennial, rather than annual, screening mammography. ${ }^{8}$ However, the National Comprehensive Cancer Network (NCCN) guidelines continue to recommend annual screening with mammography for women at average risk beginning at age $40 .{ }^{9}$ Table 1 provides a more in-depth view of breast cancer screening guidelines from different health and government organizations.

Given questions regarding optimal breast cancer screening guidelines, the Wisconsin Breast Cancer Task Force (WBCTF), a statewide coalition of breast health organizations, providers, representatives, and advocates, published data in 2012 regarding breast cancer screening attitudes, beliefs, and practices of primary care providers in Dane County, Wisconsin, which includes Madison, the second largest city in Wisconsin. ${ }^{15}$ This report found diverse breast cancer screening beliefs and recommendations with higher than expected confidence in breast self-exam and lower than expected confidence in mammography. In our study, we sought to understand preferences for breast cancer screening practices on a larger population across the state with an emphasis on more urban and diverse areas in southeastern Wisconsin through repeat survey of primary care providers in five large health systems. We wanted to utilize this survey data to assess current compliance to screening guidelines, utilizing the hypothesis that there are still discrepancies between primary care provider surveillance preferences, recommendations, and screening guidelines and that these discrepancies may be related to discrete provider factors that may help to guide future education to improve screening guideline compliance.

\section{METHODS}

Information was obtained by sending a voluntary 46-question survey in 2018 about breast cancer screening for average-risk women to five health systems in southeastern Wisconsin: Columbia, St. Mary's, ProHealth Care, Progressive Health Center, and Aurora Health Care. The questionnaire was the same one developed from the WBCTF in 2012 that was sent to providers in Dane County, Wisconsin. The Wisconsin Department of Safety and Professional Services provided contact information for providers within these health systems. The survey was sent to specialties that are impacted by cancer screening guidelines and refer their patients for mammograms, such as family medicine, internal medicine, and obstetrics and gynecology. Providers sampled included medical doctors, nurse practitioners (NPs), physician assistants (PAs), and midwives.

The survey was built in UW Qualtrics, an online survey tool. An anonymous survey link was sent to the healthcare providers by each institution between January and August 2018. Up to two email reminders were sent roughly 10 days apart to encourage responses. Invited respondents had 1 month to respond, and data collection was complete in September 2018. Incomplete questionnaires were accepted. The survey took approximately $15 \mathrm{~min}$ for providers to complete. The survey focused on perceived efficacy of various breast cancer screening modalities as well as the influence of the following national screening guidelines: USPSTF, American Cancer Society (ACS), American College of Obstetricians and Gynecologists (ACOG), American Academy of Family Physicians (AAFP), NCCN, and the American College of Radiology (ACR). The survey also asked providers to describe their actual screening practices for breast cancer screening in average-risk women.

Descriptive statistics were computed on perceived efficacy of various breast cancer screening modalities and beliefs in national screening guidelines, and a chi-square test was used to compare these perspectives by professional degrees (i.e., physician versus non-physician clinician). All analyses were performed with IBM SPSS statistical software, version 25 (IBM Corp., Armonk, NY). The study was granted exemption from IRB approval.

\section{RESULTS \\ Provider-Specific Variables}

In total, the survey was sent to 1031 providers and 295 people responded to the survey, for a response rate of $28.6 \%$. Incomplete surveys were accepted, and therefore, each question was analyzed individually with its own " $n$." Several respondents had to be excluded due to no longer practicing medicine $(9 / 265)$ or not seeing female patients over the age of 30 in their practice (1/254). Of 265 respondents, $64.1 \%(170 / 265)$ were doctors, $25.7 \%$ (68/265) were NPs, 5.3\% (14/265) were 
Table 1 Breast Cancer Screening Guidelines in 2018

\begin{tabular}{|c|c|c|c|c|c|c|}
\hline \multirow[t]{2}{*}{ Organization } & \multicolumn{3}{|l|}{ Mammography } & \multirow{2}{*}{$\begin{array}{l}\text { Interval for } \\
\text { mammography }\end{array}$} & \multirow[t]{2}{*}{ Clinical breast exam } & \multirow{2}{*}{$\begin{array}{l}\text { Self-breast } \\
\text { exam }\end{array}$} \\
\hline & $40-49$ & $\begin{array}{l}50- \\
74\end{array}$ & $75+$ & & & \\
\hline $\begin{array}{l}\text { US Preventive Task } \\
\text { Force }^{8}\end{array}$ & Individualized & Yes & Insufficient evidence & Biennial & Insufficient evidence & $\begin{array}{l}\text { Not } \\
\text { recommended }\end{array}$ \\
\hline $\begin{array}{l}\text { American College of } \\
\text { Obstetricians and } \\
\text { Gynecologists }{ }^{10}\end{array}$ & Offered & Yes & $\begin{array}{l}\text { Shared decision- } \\
\text { making process }\end{array}$ & Every $1-2$ years & $\begin{array}{l}\text { Offer } 1-3 \text {-year screening } \\
\text { for women aged } 25- \\
39 \text { years; annually, } 40+\end{array}$ & $\begin{array}{l}\text { Not } \\
\text { recommended }\end{array}$ \\
\hline $\begin{array}{l}\text { American Cancer } \\
\text { Society }\end{array}$ & $\begin{array}{l}\text { Offered, } 40-44 \\
\text { Recommended, } \\
45-49\end{array}$ & Yes & $\begin{array}{l}\text { Continue screening } \\
\text { until life expectancy } \\
<10 \text { years }\end{array}$ & $\begin{array}{l}\text { Annual, 40-54; an- } \\
\text { nual/biennial, 55+ }\end{array}$ & Not recommended & $\begin{array}{l}\text { Not } \\
\text { recommended }\end{array}$ \\
\hline $\begin{array}{l}\text { National Comprehensive } \\
\text { Cancer Network }\end{array}$ & Yes & Yes & $\begin{array}{l}\text { Continue screening } \\
\text { until life expectancy } \\
<10 \text { vears }\end{array}$ & Annual & $\begin{array}{l}\text { Every } 1-3 \text { years for age } \\
25-39 \text {, then annually, } 40+\end{array}$ & $\begin{array}{l}\text { Not } \\
\text { recommended }\end{array}$ \\
\hline $\begin{array}{l}\text { American College of } \\
\text { Radiology }{ }^{13}\end{array}$ & Yes & Yes & $\begin{array}{l}\text { Continue screening } \\
\text { until life expectancy } \\
<5-7 \text { years }\end{array}$ & Annual & Not addressed & Not addressed \\
\hline $\begin{array}{l}\text { American College of } \\
\text { Physicians }\end{array}$ & Individualized & Yes & No & Biennial & Not recommended & $\begin{array}{l}\text { Not } \\
\text { recommended }\end{array}$ \\
\hline $\begin{array}{l}\text { American Academy of } \\
\text { Family Physicians }\end{array}$ & Individualized & Yes & Insufficient evidence & Biennial & Insufficient evidence & $\begin{array}{l}\text { Not } \\
\text { recommended }\end{array}$ \\
\hline
\end{tabular}

PAs, and 1.5\% (4/265) were midwives; $3.4 \%$ (9/265) of respondents answered "none of the above, or I no longer practice in Southeastern Wisconsin." Of physicians, 65.3\% (111/170) practiced family medicine, $25.3 \%$ (43/170) practiced internal medicine, and 9.4\% (16/170) practiced obstetrics and gynecology. Most $(72.7 \%, 194 / 267)$ responders were employees of large health systems, $13.5 \%$ (36/267) were employees in organizations not associated with a university, 7.1\% (19/267) were full or part-owner of a physician practice, $2.6 \%$ (7/267) were employees of a physician-owned practice, and the remainder $(2.6 \%, 7 / 267)$ claimed affiliations with a group or staff model HMO, university hospital, clinic, or other. Over half $(56.6 \%, 81 / 143)$ of physicians surveyed were female, and the majority $(95 \%, 57 / 60)$ of non-physician clinicians (NP, PA, midwives) surveyed were female. The majority $(84.1 \%, 175 /$ 208 ) of responders said their primary care practice agreed to implement national guidelines for breast cancer screening. Most respondents $(59 \%, 124 / 210)$ received annual feedback regarding their rates of breast cancer screening compliance, while $37.1 \%$ (78/210) did not and 3.8\% (8/210) were unsure. There was no statistically significant difference between provider type and time from last continuing medical education (CME) credit on breast cancer screening.

\section{Patient Population}

The average patient population of the providers surveyed had the following racial distribution: $67.7 \%$ white, $19.63 \%$ black, $14.87 \%$ Hispanic or Latina, $5.45 \%$ Asian, and $2.14 \%$ American Indian or Alaska Native. Nearly three fourths (74.49\%) of patients seen by these providers were $40+$ years old.

Most providers $(77.7 \%, 136 / 175)$ stated that $0-5 \%$ of their patients were uninsured; $19.4 \%$ (34/175) believed that their uninsured patient population was between 6 and $26 \%$ of all their patients, and $46.1 \%(89 / 193)$ of respondents stated that between 6 and 26\% of their patients were insured by Medicaid or other local health coverage assistance programs.

\section{Perceived Efficacy of Breast Cancer Screening Modalities}

Nearly half $(48.8 \%, 119 / 244)$ of providers believed that the clinical breast exam is "somewhat effective" with $35.2 \%$ (86/ 244) stating that it is not effective; the response was similar for breast self-exam with providers answering 49.6\% (121/244) and $35.2 \%$ (86/244), respectively. Mammography was believed to be "very effective" for $74.6 \%$ (182/244) of respondents for patients aged 50-74 years old; this percentage decreased to $47.5 \%$ (116/244) for patients aged $40-49$ years old and $20.1 \%$ (49/244) for patients greater than 75 years old. Non-physician clinicians were statistically more likely to believe in the effectiveness of clinical breast exams, self-breast exams, and mammograms for women of all ages compared to physicians $(p<.001)$ (Fig. 1).

\section{Influence of Guidelines on Screening Practice}

The USPSTF was reported as being "very influential" for $60.5 \%$ (144/238) of providers. The next most influential organization was the ACS with $46.8 \%$ (110/235) of respondents reporting it as "very influential," followed by $40.4 \%(95 / 235)$ for the AAFP and the ACOG at $39.7 \%$ (93/234). When this was divided by provider type, non-physician clinicians favored ACS guidelines over USPSTF recommendations. Roughly 5\% (11/238) of those questioned were not familiar with USPSTF guidelines and 39.5\% (92/233) were unaware of NCCN guidelines. Despite having these organizational guidelines, most respondents $(83.1 \%, 197 / 237)$ only "usually" followed the guidelines they find most influential, while $12.7 \%(30 / 237)$ of providers responded that they "always" followed their preferred guidelines (Fig. 2).

\section{Screening Practices}

For patients $40-49$, the majority $(75.6 \%, 170 / 225)$ of providers surveyed performed clinical breast exams, most 


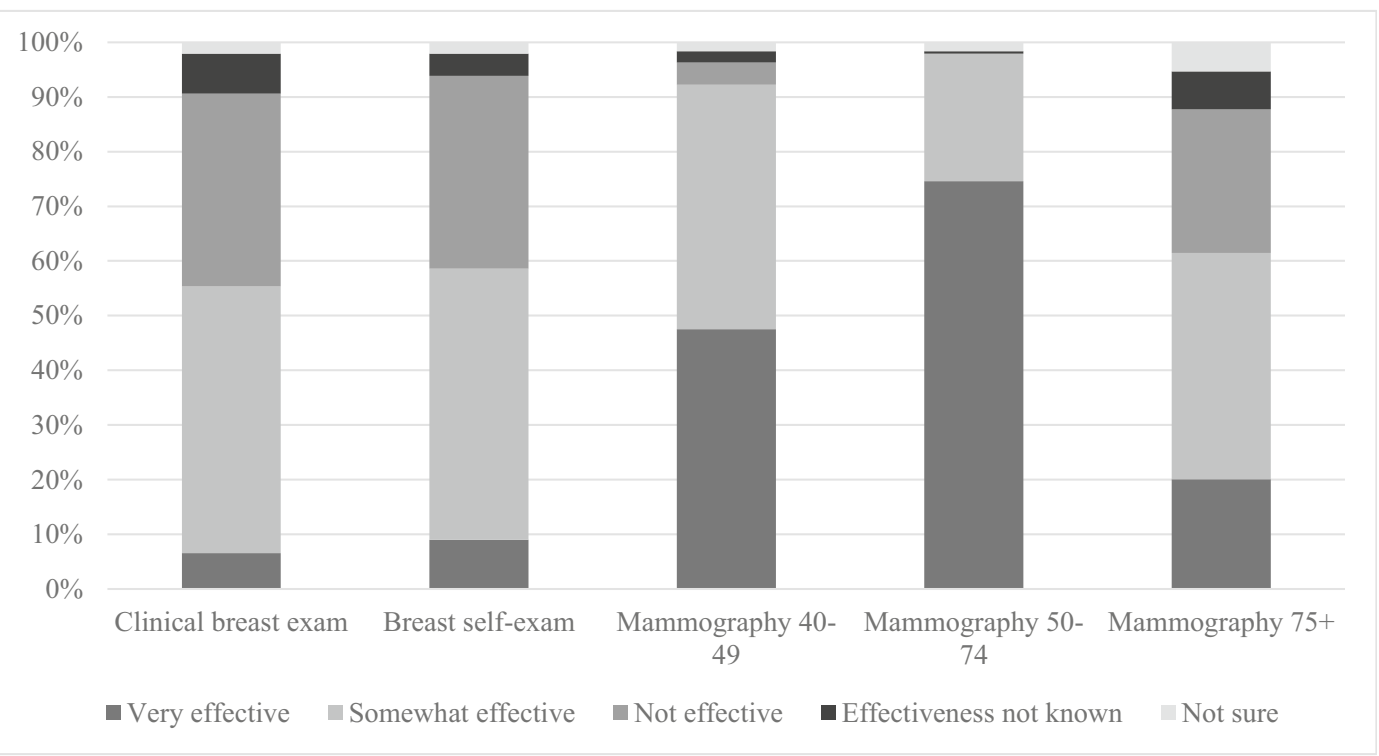

Fig. 1 Beliefs of PCPs regarding breast cancer screening effectiveness.

$(91.8 \%, 156 / 170)$ of which were done annually. Over half $(58.5 \%, 131 / 224)$ of providers encouraged breast self-exams in this patient population. Mammography was recommended to this population by $80.7 \%$ (197/244) of those surveyed; the screening interval most commonly recommended was annually at $72.5 \%$ (140/193). Only $12.1 \%$ (27/224) of providers did not recommend mammography at all for women $40-49$ years old.

For women $50+$ years old, $78.7 \%$ (177/225) of respondents performed clinical breast exams, again most $(92 \%, 160 / 174)$ of which were done annually. Self-breast exams were recommended by $61.2 \%$ (137/224) of providers for this age group. Nearly all responders $(99.6 \%, 223 / 224)$ recommended mammography in women 50+ years old. Most $(77.7 \%, 167 / 215)$ of those who recommended screening recommended annual screening, while $20.5 \%$ (44/215) recommended biennial mammography. Almost half $(45.1 \%, 133 / 295)$ of responders never stopped recommending mammography based on age. However, of the $54.9 \%(162 / 295)$ that did, the mean age was 77.3 years old.

When survey responses were further divided into physician versus clinician (NP, PA, midwives), there was no statistically significant difference in the use of clinical breast exams or self-breast exams. Mammography was more likely to be recommended annually for women aged 40-49 rather than every 2 years by clinicians as compared to physicians $(p<.001)$. Otherwise, there was no statistically significant difference in mammography screening practices.

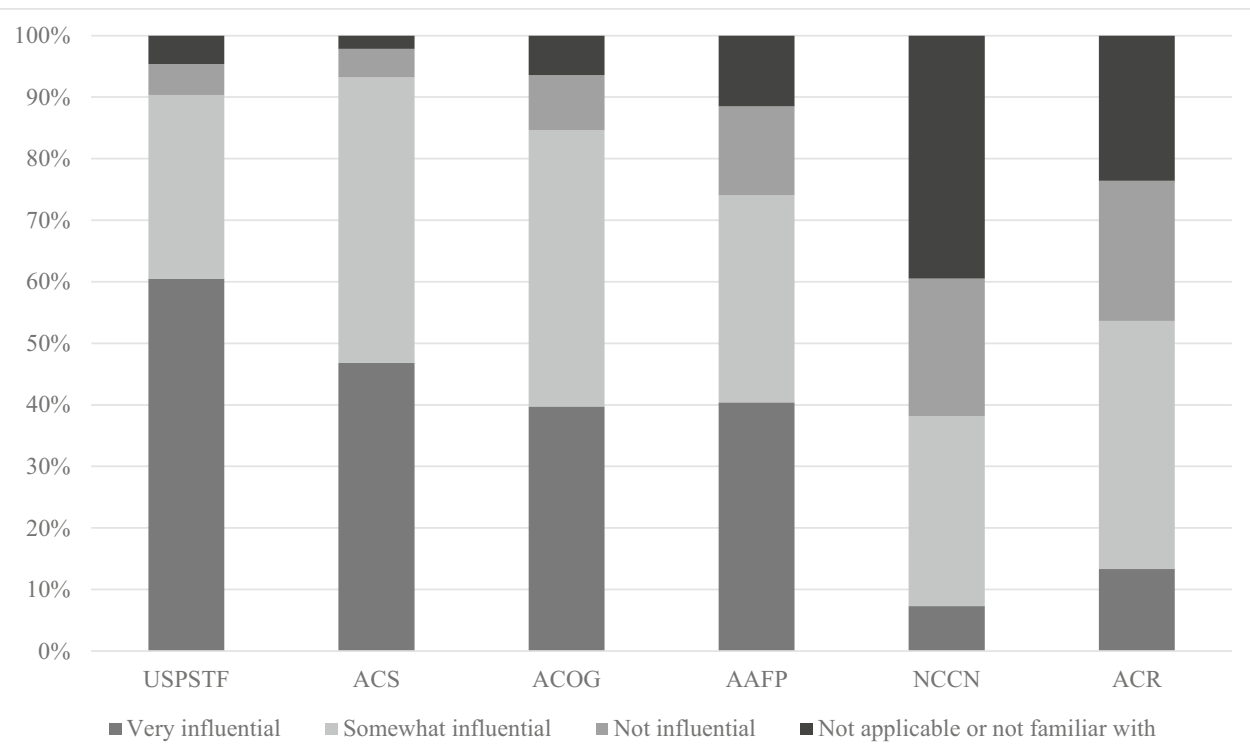

Fig. 2 Reported influence of breast cancer screening guidelines in clinical practice. USPSTF, United States Preventive Services Task Force; ACS, American Cancer Society; ACOG, American College of Obstetricians and Gynecologists; AAFP, American Academy of Family Physicians; NCCN, National Comprehensive Cancer Network; ACR, American College of Radiology. 


\section{DISCUSSION}

Primary care providers often rely on national screening guidelines to ensure that evidence-based cancer screening practices are being utilized. However, given the need to balance intricate benefits and risks of screening, there are often contradicting guidelines that can leave providers confused. We sought to discover breast cancer screening practices for average-risk women by PCPs in Wisconsin with hopes of finding patterns that would allow us to improve evidence-based screening adherence.

Similar to the WBCTF survey in 2012, Wisconsin primary care providers continue to overestimate the efficacy of clinical and self-breast exams as well as overuse them in practice. ${ }^{15}$ Even though the majority of providers found USPSTF guidelines to be the most influential, most providers surveyed continue to perform clinical breast exams and encourage self-breast exams. While NCCN guidelines recommend patient "breast awareness," which may justify the recommendation for best self-examinations, almost $40 \%$ of providers surveyed were not aware of such guidelines. ${ }^{12}$ This problem is not isolated to Wisconsin clinicians alone, as similar findings were discovered in a study looking at providers in Massachusetts in 2015 where $70 \%$ of those surveyed were teaching breast self-exams despite guideline recommendations against them. ${ }^{16}$

Although USPSTF guidelines state with a grade $\mathrm{C}$ recommendation that the decision to screen before the age of 50 should be "an individual one," almost half of the providers surveyed recommended mammograms to women aged 40 49. ${ }^{8}$ This, in part, might be due to the ACS guidelines that recommend screening with mammography starting at age 45 . The consequences of this augmented screening practice include possible increased harm to patients as well as greater costs, without clear benefit of reduced mortality from breast cancer. For instance, it is estimated that current breast cancer screening practices are costing $\$ 7.8$ billion/year, but if USPSTF guidelines alone were to be implemented, the cost could decrease to $\$ 3.5$ billion/year. ${ }^{17}$

We did find that non-physician clinicians in our study favored annual mammograms rather than biennial for women aged 40-49 when compared to physicians. This was also found in a study among primary care providers in Minnesota, as non-physician providers were more likely to recommend mammography in patients $40-49$ years old. ${ }^{18}$ It is not clear if this is due to differences in training, increased beliefs of efficacy, or one of many other variables. Gender-related bias might be present as the majority of our clinicians surveyed were female and a previous study evaluating screening practices and provider characteristics found that female providers, as well as providers in a community-based practice and providers who had been out of training for longer, were more likely to recommend mammograms in women aged 40-49. ${ }^{19}$

Since multiple organizations recommend shared providerpatient decision making for when to initiate screening, it is possible that patients are the reason for more aggressive screening practices. In a patient survey collected at the Mayo Clinic in Minnesota and Arizona, $77 \%$ of women believed that annual mammogram and clinical breast exams were recommended for breast cancer screening; although the percentage decreased after being informed of national guidelines, more than half of the patients still planned on receiving annual breast exams and mammograms. ${ }^{20}$ Due to this, it is important that providers are able to educate their patients and provide medical recommendations. The Gail model is a risk assessment tool that providers can use to help quantify breast cancer risk for individual patients, which can be valuable during the shared decision making process. ${ }^{21}$

Our results revealed that providers are not following the national guidelines they view as being the most influential. Wisconsin providers are not alone in this disconnect between guideline beliefs and actual screening recommendations that are made to their patients. In one study looking at guideline compliance in primary care providers in Cleveland, Ohio, it was revealed that despite the majority of providers surveyed being heavily influenced by USPSTF guidelines, nearly two thirds of the providers continued to screen women aged 4049 years for breast cancer with mammography. ${ }^{19}$ More aggressive screening practices despite provider preference for USPSTF guidelines were also noted in an earlier study that evaluated women's health physicians at four health institutions in the Northeastern United States. ${ }^{22}$ It has been noted that provider's beliefs and recommendations are only modestly associated with actual screening practices, implying that there are other factors at play. ${ }^{23}$ While we did not address this specifically, some of the motivation for increased screening could be through individual institutions and physician reimbursement as well. ${ }^{24}$ Further evaluation would be beneficial in evoking change and improving screening guideline compliance by primary care providers.

One limitation of our study was the number of participants. Although our response rate of $28.6 \%$ is consistent with the response rate of other Web-based surveys, ideally there would have been a greater response rate with more diversity in provider type to increase power. ${ }^{25}$ Furthermore, there is no data surrounding characteristics of respondents and non-respondents, which creates the possibility of self-selection bias and lack of generalizability. Another weakness was that the data surrounding provider screening practices was collected via survey rather than chart review. Although our results are consistent with other studies, our provider population was isolated to one state and it is unclear if geographic provider or patient characteristics might make this data less generalizable.

Our survey revealed that providers find multiple different screening guidelines influential but favor the USPSTF. However, despite finding guidelines important, they are frequently not being followed. Primary care providers in Wisconsin continue to overestimate the efficacy of clinical and selfbreast exams as well as overuse these in clinical practice. 
Although nearly $40 \%$ of respondents were unaware of NCCN guidelines, their recommendation for breast "self-awareness" might serve well as a middle ground when it comes to provider and patient's desire for continued self-breast exams despite lack of mortality benefit. Results suggest that mammography is offered to patients more frequently than recommended in the guidelines deemed most influential by the providers surveyed in this study. Practice guidelines are vital for the improvement of public health as well as ensuring clinical standard of care; however, differing recommendations might be leading to poor guideline adherence by providers and patients alike. It might be that the adoption of a single guideline recommendation would ultimately improve evidence-based screening by providers. Further research needs to be done to investigate the reason preferred guidelines are not being followed so we can improve compliance with evidence-based screening recommendations in the future.

\section{Acknowledgments:}

The Wisconsin Breast Cancer Task Force (WBCTF) contributed to this study.

Corresponding Author: Emily Nachtigal, MD; University of Wisconsin Carbone Cancer Center, Madison, WI, USA

Funding Information This study received grants from the University of Wisconsin Carbone Cancer Center (Support Grant P30 CA014520) and Centers for Disease Control and Prevention (Cooperative Agreement 5 NU58DP006328-03-00).

\section{Compliance with Ethical Standards:}

Conflict of Interest: Dr. Emily Nachtigal has nothing to disclose. Dr. Noelle LoConte reports grants from Bayer, grants from Celgene, grants from AbbVie, and personal fees from Astra Zeneca, outside the submitted work.

Sarah Kerch has nothing to disclose.

Dr. Xiao Zhang has nothing to disclose.

Dr. Amanda Parkes has nothing to disclose.

\section{REFERENCES}

1. American Cancer Society. Cancer Facts \& Figures 2018. Atlanta: American Cancer Society; 2018.

2. DeSantis CE, Ma J, Goding Sauer A, Newman LA, Jemal A. Breast cancer statistics, 2017, racial disparity in mortality by state. CA Cancer J Clin. 2017;67(6):439-48. Epub 2017/10/03. doi: https://doi.org/10. 3322/caac. 21412 .

3. Nelson HD, Fu R, Cantor A, Pappas M, Daeges M, Humphrey L. Effectiveness of Breast Cancer Screening: Systematic Review and Metaanalysis to Update the 2009 U.S. Preventive Services Task Force Recommendation. Ann Intern Med. 2016;164(4):244-55. Epub 2016/01/12. doi: https://doi.org/10.7326/M15-0969.

4. Mandelblatt JS, Stout NK, Schechter CB, van den Broek JJ, Miglioretti DL, Krapcho M, et al. Collaborative Modeling of the Benefits and Harms Associated With Different U.S. Breast Cancer Screening Strategies. Ann Intern Med. 2016;164(4):215-25. Epub 2016/01/12. doi: https://doi.org/10.7326/M15-1536. PubMed PMID: 26756606; PubMed Central PMCID: PMCPMC5079106.

5. Hall IJ, Tangka FKL, Sabatino SA, Thompson TD, Graubard BI, Breen N. Patterns and Trends in Cancer Screening in the United States. Prev Chronic Dis. 2018;15:E97. Epub 2018/07/26. doi: https://doi.org/10. 5888/pcd15.170465. PubMed PMID: 30048233; PubMed Central PMCID: PMCPMC6093265.

6. Saletti $\mathbf{P}$, Sanna $\mathbf{P}$, Gabutti L, Ghielmini $\mathbf{M}$. Choosing wisely in oncology: necessity and obstacles. ESMO Open. 2018;3(5):e000382. Epub 2018/07/11. doi: https://doi.org/10.1136/esmoopen-2018000382. PubMed PMID: 30018817; PubMed Central PMCID: PMCPMC6045771.

7. Wilt TJ, Harris RP, Gaseem A, Physicians HVCTFotACo. Screening for cancer: advice for high-value care from the American College of Physicians. Ann Intern Med. 2015;162(10):718-25. doi: https://doi. org/10.7326/M14-2326.

8. Siu AL, Force USPST. Screening for Breast Cancer: U.S. Preventive Services Task Force Recommendation Statement. Ann Intern Med. 2016;164(4):279-96. Epub 2016/01/12. doi: https://doi.org/10.7326/ M15-2886.

9. Helvie MA, Bevers TB. Screening Mammography for Average-Risk Women: The Controversy and NCCN's Position. J Natl Compr Canc Netw. 2018;16(11): 1398-404. doi: https://doi.org/10.6004/jnccn.2018.7081.

10. Bulletins-Gynecology CoP. Practice Bulletin Number 179: Breast Cancer Risk Assessment and Screening in Average-Risk Women. Obstet Gynecol. 2017;130(1):e1-e16. doi: https://doi.org/10.1097/AOG. 0000000000002158

11. Smith RA, Andrews KS, Brooks D, Fedewa SA, Manassaram-Baptiste D, Saslow D, et al. Cancer screening in the United States, 2018: A review of current American Cancer Society guidelines and current issues in cancer screening. CA Cancer J Clin. 2018;68(4):297-316. Epub 2018/05/30. doi: https://doi.org/10.3322/caac.21446.

12. NCCN Clinical Practice Guidelines in Oncology: Breast Cancer Screening and Diagnosis 2018 [12/17/18]. Available from: https://www.nccn.org/ professionals/physician_gls/pdf/breast-screening.pdf.

13. Mainiero MB, Moy L, Baron P, Didwania AD, diFlorio RM, Green ED, et al. ACR Appropriateness Criteria. J Am Coll Radiol. 2017;14(11S):S383-S90. doi: https://doi.org/10.1016/j.jacr.2017.08. 044.

14. Jordan V, Khan M, Prill D. Breast Cancer Screening: Why Can't Everyone Agree? Prim Care. 2019;46(1):97-115. Epub 2018/12/22. doi: https://doi.org/10.1016/j.pop.2018.10.010.

15. Jones N, Weeth-Feinstein L, Mroz S. Breast Cancer Task Force Provider Survey. Report of Findings: Dane County 2012.

16. Loh KP, Stefan MS, Friderici J, Tan EK, Ogunneye O, Kleppel R, et al. Healthcare Professionals' Perceptions and Knowledge of the USPSTF Guidelines on Breast Self-Examination. South Med J. 2015;108(8):45962. doi: https://doi.org/10.14423/SMJ.0000000000000318.

17. O'Donoghue C, Eklund M, Ozanne EM, Esserman LJ. Aggregate cost of mammography screening in the United States: comparison of current practice and advocated guidelines. Ann Intern Med. 2014;160(3): 145. doi: https://doi.org/10.7326/M13-1217. PubMed PMID: 24658691; PubMed Central PMCID: PMCPMC4142190.

18. Martin K, Vogel RI, Nagler RH, Wyman JF, Raymond N, Teoh D, et al. Mammography Screening Practices in Average-Risk Women Aged 40-49 Years in Primary Care: A Comparison of Physician and Nonphysician Providers in Minnesota. J Womens Health (Larchmt). 2020;29(1):91-9. Epub 2019/07/16. doi: https://doi.org/10.1089/jwh.2018.7436.

19. Martinez KA, Deshpande A, Ruff AL, Bolen SD, Teng K, Rothberg MB. Factors Associated with Routine Recommendation of Mammography for Women Aged 40-49: Provider Characteristics and Screening Influences. South Med J. 2017;110(2):129-35. doi: https://doi.org/10.14423/SMJ. 0000000000000598

20. Mehta JM, MacLaughlin KL, Millstine DM, Faubion SS, Wallace MR, Shah AA, et al. Breast Cancer Screening: Women's Attitudes and Beliefs in Light of Updated United States Preventive Services Task Force and American Cancer Society Guidelines. J Womens Health (Larchmt). 2018. Epub 2018/09/11. doi: https://doi.org/10.1089/jwh.2017.6885.

21. The Breast Cancer Risk Assessment Tool National Cancer Institute 2017 [updated 12/2017; cited $20201 / 4 / 2020]$. Available from: https:// bcrisktool.cancer.gov/index.html.

22. Haas JS, Sprague BL, Klabunde CN, Tosteson AN, Chen JS, Bitton A, et al. Provider Attitudes and Screening Practices Following Changes in Breast and Cervical Cancer Screening Guidelines. J Gen Intern Med. 2016;31(1):52-9. https://doi.org/10.1007/s11606-015-3449-5. PubMed PMID: 26129780; PubMed Central PMCID: PMCPMC4700005.

23. Haas JS, Barlow WE, Schapira MM, MacLean CD, Klabunde CN, Sprague BL, et al. Primary Care Providers' Beliefs and Recommendations and Use of Screening Mammography by their Patients. J Gen Intern Med. 2017;32(4):449-57. Epub 2017/01/09. https://doi.org/10.1007/ 
s11606-016-3973-y. PubMed PMID: 28070772; PubMed Central PMCID: PMCPMC5377895.

24. Grady D, Redberg RF. Physician Adherence to Breast Cancer Screening Recommendations. JAMA Intern Med. 2017;177(6):763-4. doi: https:// doi.org/10.1001/jamainternmed.2017.0458.

25. Blumenberg C, Barros AJD. Response rate differences between web and alternative data collection methods for public health research: a systematic review of the literature. Int J Public Health. 2018;63(6):76573. Epub 2018/04/24. doi: https://doi.org/10.1007/s00038-018-11084 .

Publisher's Note: Springer Nature remains neutral with regard to jurisdictional claims in published maps and institutional affiliations. 